\title{
EFEITO DA FORMONONETINA (7 Hidroxi, 4'metoxi Isoflavona) NA COLONIZAÇÃO MICORRÍZICA E CRESCIMENTO DO MILHO EM SOLO CONTENDO EXCESSO DE METAIS PESADOS ${ }^{(\mathbf{1})}$
}

\author{
J . O. SIQUEIRA (2), M. A. M. PEREIRA(3), \\ J . B. P.SIMÃO ${ }^{(4)} \&$ F. M.S. MOREIRA ${ }^{(2)}$
}

\begin{abstract}
RESUMO
O excesso de metais pesados contamina o solo, exercendo impacto negativo sobre os microrganismos e ação tóxica sobre as plantas, dificultando a revegetação e reabilitação de áreas degradadas. No presente estudo, avaliou-se - efeito da aplicação do isoflavonóide formononetina (7 hidroxi, 4'metoxi isoflavona) no crescimento e absorção de metais pelo milho (Zea mayz L.) em mistura de solo com proporções crescentes de um solo contaminado que continha 16.904, 194, 219 e $836 \mathrm{mg} \mathrm{dm}^{-3}$ de solo de Zn, Cd, Pb e Cu, respectivamente. Esse solo foi diluído com solo não contaminado para obter misturas com $0 ; 2,5 ; 5,0 ; 7,5$ e $10,0 \% \mathrm{p} / \mathrm{p}$ do solo contaminado. Nas misturas de solo, infestadas com propágulos de fungos micorrízicos, foi plantado milho, com e sem a aplicação de solução de formononetina sintética ( $5 \mathrm{gg} \mathrm{L}^{-1}$ ) equivalente a $400 \mathrm{\mu g} \mathrm{kg}^{-1}$ de solo. Verificou-se um efeito depressivo acentuado da elevação da contaminação do solo na colonização micorrízica e no cresci mento das plantas. A formononetina estimulou a colonização nos níveis mais baixos de contaminação e exerceu efeito positivo no crescimento do milho. A absorção dos metais, em especial deZn eCd, aumentou com a elevação da contaminação, sendo os teores de $\mathrm{Zn}$ menores nas plantas com formononetina, enquanto os teores de Fe foram maiores nestas plantas até $\mathbf{7 , 5 \%}$ de solo contami nado. Os resultados indicam que a formononetina reduz, de modo indireto, por meio da micorriza, os efeitos adversos do excesso de metais no solo, especialmente de Zn no milho. $O$ favoreci mento da formação de micorriza diminui a absorção de $\mathrm{Zn}$ e aumenta a de $\mathrm{Fe}$, podendo ser este o mecanismo responsável pela ação amenizante da formononetina na toxidez de metais pesados no mil ho. Conclui-se que o uso da formononetina pode facilitar a revegetação de solos contaminados com metais pesados.
\end{abstract}

Termos de indexação: poluição do solo, micorrizas, simbioses radiculares, flavonóides, absorção mineral, fitotoxidez.

(1) Trabal ho financiado pelo convênio CMM/FAEPE e FAPEMIG. Apresentado na FertBIO'98 em Caxambú. Recebido para publicação em março de 1998 e aprovado em fevereiro de 1999.

(2) Professores Titular e Adjunto do Departamento de Ciência do Solo, Universidade Federal de Lavras (UFLA). CEP $37200-000$ Lavras (MG). Bolsistas do CNPq.

(3) Engenheiro-Agrônomo, ex-bolsista do Departamento de Ciência do Solo, UFLA.

(4) Engenheiro-Agrônomo, Doutorando em Solos e Nutrição de Plantas, Departamento de Ciência do Solo, UFLA. Bolsista do CAPES-PICDT. 


\begin{abstract}
SUMMARY: EFFECT OF FORM ONONETIN (7 Hydroxy 4'methoxy I soflavona) ON MYCORRHIZAL COLONIZATION AND GROWTH OF CORN IN SOIL WITH EXCESS OF HEAVY METALS
\end{abstract}

\begin{abstract}
Theexcess of heavy metal s contaminating soi ls is responsiblefor a negativei mpact on microorganisms and toxicity on plants, hence turning revegetation and rehabilitation of areas degraded by thesemetal s very difficult. In thepresent study, theeffects of theisoflavonoid formononetin (7 hydroxy 4'methoxy isoflavona) on growth and metal uptake by corn (Zea mays $L$.) werestudied in soil-mixes with increasing proportions of a contaminated soil with 16.904; 194; 219 and $836 \mathrm{mg} \mathrm{dm}^{-3}$ of soil of $\mathrm{Zn}, \mathrm{Cd}, \mathrm{Pb}$ and $\mathrm{Cu}$, respectively. A sample ef soil was diluted in a non-contami nated soil at therates of $0 ; 2.5 ; 5.0 ; 7.5$ and $10.0 \%$ by weight of the contaminated soil. Soil-mi xes wereinfested with propagules of arbuscular mycorrhiza fungi (AMF), sown with corn either in presence or absence of formononetin solution at $5 \mathrm{mg} \mathrm{L}^{-1}$, applied at an equival ent rate of $400 \mathrm{mg} \mathrm{kg}^{-1}$ soil. A deppressive effect of soil contamination on AMF colonization and plant growth was found. Application of formononetin enhanced root colonization at low to moderate levels of contamination and also affected corn dry matter yiedd. Uptake of $\mathrm{Zn}$ and $\mathrm{Cd}$ increased markedly with increasing levels of soil contamination. Zn uptake was lower in formononetin-treated plants, whereas Fe uptake was enhanced by this treatment up to $7.5 \%$ of contaminated soil. Theseresults indicatethat formononetin growth effect on corn under a heavy metal-stressed condition is mediated by its effects on mycorrhiza formation. Formononetin's indirect decrease of $\mathrm{Zn}$ uptake and enhancement of Fe uptakeseems to be the mechanism by which this compound ameliorates heavy metal toxicity on corn. In concl usion, the use of formononetin may facilitaterevegetation on heavy-metal polluted soils.
\end{abstract}

Index terms: soil pollution, mycorrhizae, root symbiosis, flavonoids, mineral uptake, phytotoxicity.

\section{INTRODUÇÃO}

A poluição da biosfera com metais pesados, decorrente de ações antrópicas, representa, atual mente, sérios problemas ambientais e de saúde pública em várias regiões do mundo. No solo, o excesso de metais é causado por inúmeras fontes, sendo as atividades de mineração e transformação industrial de materiais que contêm esses metais exemplo das principais fontes de contaminação (Alloway, 1990). No solo, os diferentes metais ocorrem em formas distintas, como livres na solução, compl exos solúveis, íons trocáveis ligados à matéria orgânica, preci pitados ou fazendo parte da estrutura dos minerais e, quando em excesso, exercem enorme impacto sobre a vegetação, microrganismos e processos funcionais do ecossistema (Valsecchi et al., 1995). A toxidez de um metal no solo depende de sua disponibilidadea qual é controlada pelos fatores físico-químicos e biológicos do solo que regulam a concentração do metal em solução.

Dentre os vários fenômenos bi ol ógicos do sistema solo-planta, destacam-seas micorrizas arbusculares (MAs) que são partes integrantes e funcionais das plantas. Essa simbiose mutualista exerce grande influência na nutrição e tolerância das plantas a estresses bióticos eabióticos (Siqueira \& Saggin J r., 1995). Diante da necessidade de revegetar ou da possibilidade de usar plantas no processo de descontaminação do solo (Baker et al., 1994), pelo emprego de tecnol ogias emergentes conheci das como "remediação verde" ou "fitorremediação" (Salt et al. 1995), as interações de micorrizas e metais tornamse de grande importância na restauração de ecossistemas (Diaz et al., 1996). Neste contexto, dois aspectos principais devem ser considerados. $\mathrm{O}$ primei ro trata dos efeitos dos metais sobre os fungos micorrízicos e sua simbiose, enquanto o segundo trata dos efeitos dos fungos na absorção e transferência de metais do solo para a planta e na própria planta e, de suas conseqüências para a tolerância das plantas ao excesso de metais pesados (Nogueira, 1996; Leyval et al., 1997).

As mi corrizas arbusculares podem ocorrer mesmo em solo al tamente contami nado com metais pesados, porém, em geral, a col onizaçãoémuito reduzida nessas condições. Vários metais pesados são fungitóxicos, reduzindo a germinação dos esporos, crescimento micelial e, conseqüentemente, a col onizaçãomicorrízica (Nogueira, 1996). Griffioen et al. (1994) verificaram que, em local próximo a uma refinaria de $Z n$ e contami nado com Zn e Cd, a Agrostis capilaris, uma espécie empregada em programas de reabilitação de sol os contaminados com metais pesados (Vangronsveld et al., 1995), encontrava-se bastante colonizada, devendo, portanto, beneficiar-se da simbiose. 
Os efeitos das MAs na absorção e translocação demetais na planta são ainda pouco conhecidos, mas, dependendo da planta, da concentração do metal no meio de crescimento e possivel mente da espécie de fungo, essa simbiose pode aumentar ou diminuir a absorção de certos metais.

Segundo Weissenhorn et al. (1995), a colonização radicular do milho em solo contaminado aumentou a massa vegetal ereduziu a absorção de Cd, Zn eCu na parte aérea e raízes, fato também relatado para outras espécies (Dueck et al., 1986; Schüepp et al., 1987; Nogueira, 1996; Leyval et al., 1997). I stoindica que as MAs podem aliviar os efeitos adversos da fitotoxidez induzida pel o excesso de metais no sol oe se revestem de importância ecológica e, mais recentemente, tecnológica, considerandoa necessidade de reabilitar áreas poluídas com metais pesados, espalhadas por todo o mundo. Maximizar a colonização radicular de plantas em ambientes adversos, como em solos poluídos com metais pesados, é de grande interesse. I sto pode ser conseguido por meio de inoculação em grande escala o que, com o atual nível de conhecimento, é inviável, em razão da falta de inoculantecomercial de fungos MAs. No entanto, a descoberta de substâncias de origem vegetal, capazes de estimular a colonização radicular por fungos MAs, como no caso do isoflavonóide formononetina (Nair et al., 1991), oferece uma alternativa para aumentar a colonização e atividade desses fungos (Siqueira et al., 1991a; Silva J r. \& Siqueira, 1997).

Como discutido em trabalhos já citados, a col onização mi corrízica pode amenizar o estresse da fitotoxidez de metais e, à semelhança do que tem sido demonstrado para estresse induzido por resíduo de herbicida no solo (Siqueira et al., 1991b), a aplicação dessa substância pode favorecer o crescimento de plantas em solo com excesso de metais. I sto foi objeto do presente estudo, que utilizou o mil ho como planta-teste.

\section{MATE RIAL E MÉTODOS}

O estudo foi desenvolvido em casa de vegetação, do Departamento de Ciência do Sol ona U niversidade Federal de Lavras (UFLA), L avras (MG), no período de março a maio de 1996, em vasos com capacidade para 1,6 $\mathrm{L}$ de misturas de solo contaminado e não contaminado, que continham 0; 2,5; 5,0; 7,5 e 10,0\% em peso/peso de solo contaminado com metais pesados. O sol o contaminado é remanescente de um Latossolo, bastante alterado, sem distinção de horizontes, proveniente de uma área de rejeito no pátio da Companhia Mineira de Metais (CMM) em Três Marias ( $M G)$, apresentando $\mathrm{pH}$ (água) $=6,0 ; \mathrm{V}$ =64\%; matéria orgânica $=23 \mathrm{mg} \mathrm{dm}^{-3}$ e 28, 50, 16.904, 194, 219, 836 e3 $\mathrm{mg} \mathrm{dm}^{-3} \mathrm{deP}, \mathrm{K}, \mathrm{Zn}, \mathrm{Cd}, \mathrm{Pb}$,
Cu eFe, respectivamente. Fósforo, potássio e metais pesados foram extraídos por Mehlich-1, e Ca, Mg e Al por KCl $1 \mathrm{~N}$, conformeEMBRAPA (1979). O solo não contaminado empregado nas diluições é um Latossolo Vermel ho-Escuro (LE) argiloso, col etado no município de SãoSebastião da Vitória (MG), com pH (água) 4,8; $\mathrm{V}=13 \%$; matéria orgânica $25 \mathrm{mg} \mathrm{dm}^{-3}$ e 3, 41, 26, 9 e $64 \mathrm{mg} \mathrm{dm}^{-3}$ de P, K, Zn, Cu e Fe, respectivamente.

Visando equilibrar as propriedades entre os solos, oLE recebeu cal agem com cal cário dol omítico (PRNT $=100 \%$ e relação $\mathrm{Ca}: \mathrm{Mg}=4: 1$ ) para atingir $60 \%$ da saturação por bases. Vinte dias após a incubação, o solo recebeu também $100 \mathrm{mg} \mathrm{kg}^{-1}$ de $P$ na forma de superfosfato simples, deixando-se incubar por mais 14 dias. Vencido esse prazo, os solos foram misturados e devidamente homogeneizados com vistas em obter a proporção desejada, correspondente ao nível de contaminação. Em seguida, retiraramseamostras para determinação dos teores de metais extraídos pel o Mehlich-1 (Quadro 1). A densi dade de fungos micorrízicos nativos no LE era em torno de 1 esporo $\mathrm{cm}^{-3}$ desolo, sendo as espécies predominantes Glomus occultum Walker e G. clarum Nicolson e Schenck, enquanto o solo contaminado não apresentou esporos. Para contagem dos esporos, empregou-se o método de Gedermann \& Nicolson, (1963) e centrifugação em sacarose diluída em água (50\%), seguida de contagem em microscópio ester eoscópico (20x).

O experimento constou de um fatorial $5 \times 2 \mathrm{com}$ cinco repetições, sendo cinco proporções de solo contaminado na mistura obtidas pela mistura de solo e aplicação ou não de solução de formononetina sintética fornecida pela Rhizotech, Inc. (Hopewell, New J ersey-EUA). A formononetina (7 hidroxi, 4 metoxi-isoflavona) foi pesada, dissolvida em metanol (Siqueira et al., 1991a) e diluída em 5 L de água destilada obtendo-se uma solução com $5 \mathrm{mg} \mathrm{L-1}$ de formononetina. Aplicaram-se $130 \mathrm{~mL}$ dessa solução por vaso, equivalente a $400 \mathrm{mg} \mathrm{kg}^{-1}$ solo de

\section{Quadro 1. Teores de metais extraídos pelo Mehlich-1 das misturas de solo antes do crescimento do milho}

\begin{tabular}{lrrrrr}
\hline & \multicolumn{5}{c}{$\begin{array}{c}\text { Proporção de solo contaminado na } \\
\text { Mistura, \% }\end{array}$} \\
\cline { 2 - 6 } & $\mathbf{0}$ & $\mathbf{2 , 5}$ & $\mathbf{5 , 0}$ & $\mathbf{7 , 5}$ & $\mathbf{1 0 , 0}$ \\
\cline { 2 - 6 } & \multicolumn{6}{c}{ mg dm $^{-3}$ de solo } \\
\cline { 2 - 6 } & 5 & 565 & 1.104 & 3.984 & 4.510 \\
$\mathrm{Zn}$ & 1 & 4 & 10 & 17 & 20 \\
$\mathrm{Cd}$ & 2 & 54 & 100 & 127 & 160 \\
$\mathrm{Cu}$ & 0 & 12 & 22 & 46 & 54 \\
$\mathrm{~Pb}$ & 0 & &
\end{tabular}


formononetina pura. No controle, foram adicionados $130 \mathrm{~mL}$ de água destilada que continham a mesma concentração de metanol aplicado na solução com formononetina. Em ambos os casos, as aplicações foram realizadas por meio de perfurações na superfície do solo, sendo feita uma única aplicação da substância antes da transferência das plântulas. Todas as misturas de solo foram inoculadas, aplicando-se, abaixo da semente, $5 \mathrm{~mL}$ de solo com 40 esporos $\mathrm{mL}^{-1}$ de $\mathrm{G}$. etunicatum Gedermann \& Nicolson, multiplicado previamente em Brachiaria decumbens Stapf, cultivada em vasos.

Duas sementes de milho (Zea mays L., cultivar Ag 122), pré-germinadas, foram colocadas em cada vaso, com posterior desbaste, permanecendo uma planta por vaso. Durante o experimento, as plantas receberam $150 \mathrm{mg} \mathrm{kg}^{-1}$ de K e $150 \mathrm{mg} \mathrm{kg}^{-1}$ de N (em três vezes, em interval os de 10 dias). A umi dade dos vasos foi mantida ao redor de $60 \%$ do volume total de poros, por meio de pesagens periódicas eirrigação. Aos 45 dias, as plantas foram cortadas à altura da superfície do solo e avaliadas quanto à área foliar, peso da matéria seca da parte aérea e raízes e col onização micorrízica. A pós a separação das raízes do solo, foram coletadas amostras de raízes finas para a avaliação da percentagem de colonização. Para isto, as raízes foram despigmentadas com KOH (10\%), col oridas com Azul Tripano ea percentagem de comprimento de raiz colonizada determinada conforme Giovannetti \& Mosse (1980). A matéria seca das plantas foi obtida após secagem da parte aérea e raízes em estufa, com circulação de ar a 65ㄷ até peso constante, sendo, em seguida, pesada e moída para análises de metais após digestão nítricoperclórica. Os teores de $\mathrm{Cu}, \mathrm{Fe}, \mathrm{Cd}, \mathrm{Pb}$ e $\mathrm{Mn}$ foram determinados por espectrofotometria de absorção atômica e os teores de $\mathrm{Zn}$ por espectrometria de emissão atômica de plasma, induzido em argônio, nos laboratórios da Companhia Mineira de Metais, em Três Marias (MG).

Os resultados foram submetidos a análises de variância e regressão, utilizando os programas SANEST (UniversidadeF ederal dePel otas) eSAEG (Universidade Federal de Viçosa).

\section{RESULTADOS E DISCUSSÃO}

O aumento na proporção de sol o contaminado na mistura causou redução acentuada na produção de massa seca da parte aérea e da área foliar do milho (Figura 1). No nível mais alto de contaminação, a inibição foi superior a $70 \%$ em relação ao solo sem contaminação. Os efeitos da formononetina dependeram do grau de contaminação e, embora significativos $(P \leq 0,05)$ para todos os parâmetros, foram pequenos, exceto para matéria seca de raízes a $10 \%$ de contaminação, quando se mostraram mais acentuados. Segundo os resultados, a aplicação de formononetina amenizou parte do impacto negativo causado pel o excesso de metais no sol o para o milho inoculado. Como esta substância só éativa no milho na presença de propágulos defungos MAs (Siqueira et al., 1991a), seus efeitos no crescimento foram via estímulo à col onização mi corrízica (F igura 2).

Tal como verificado para os parâmetros de crescimento, a contaminação do sol otambém exerceu efeito negativo na colonização micorrízica do milho (Figura 2). No nível mais alto de contaminação, a colonização foi reduzida em $75 \%$ em relação ao solo controle sem contaminantes, mesmo na presença de formononetina. Nosolo não contaminado, a aplicação dessa substância aumentou em quase $50 \%$ a col onização das raízes, confirmando os resultados de vários outros estudos com estes flavonóides em milho (Siqueira et al., 1991b; Silva J r. \& Siqueira, 1997). No entanto, esses incrementos diminuíram com a el evação da proporção de solo contaminado, sendo inexistente a $10 \%$. Ainda assim, a aplicação de formononetina teve efeito sobre outros parâmetros avaliados.

O efeito adverso do excesso de metais sobre os microrganismos do solo já é bastante conhecido e evidenciado (Valsecchi et al., 1995), inclusiveno solo utilizado no presente estudo (Dias J r. et al., 1998). Altas concentrações de metais no solo reduzem a germinação dos esporos e o crescimento micelial (Nogueira, 1996; Leyval et al., 1997) e, como conseqüência, a col onização das raízes pel os fungos micorrízicos arbusculares, como já verificado para o milho por Vidal et al. (1996). Tais autores concluíram que o desenvol vimento da micorriza é mais sensível ao excesso de metais que o crescimento da planta.

Os teores dos diversos metais na massa seca da parte aérea e raízes do milho aumentaram proporcional mente com el evação da contaminação, especialmenteo Zn eCd (Figura 3). Plantas de milho com formononetina apresentaram teores mais baixos de $\mathrm{Zn}$ tanto nas raízes quanto na parte aérea. $\mathrm{Em}$ solo contaminado, as plantas que receberam o isoflavonói de continham em torno de $20 \%$ menos Zn na parte aérea do que aquelas que não receberam a substância. Em termos gerais, o milho apresentou duas vezes mais $Z n$ nas raízes que na parte aérea. Verificou-se que as plantas que cresceram em baixa contaminação já apresentavam teores desse elemento na matéria seca acima daqueles considerados críticos para toxidez, $400 \mathrm{mg} \mathrm{kg}^{-1}$ de Zn na massa seca, conforme Barceló \& Poschienrieder (1992). I sto corrobora os resultados de crescimento, cujos efeitos depressivos já são evidentes neste nível de contaminação. Tem sido sugerido que a redução na absorção de metais ou retenção destes nas raízes col onizadas pel os fungos micorrízi cos confere proteção das plantas ao excesso de metais no solo (Leyval et al., 1997). 


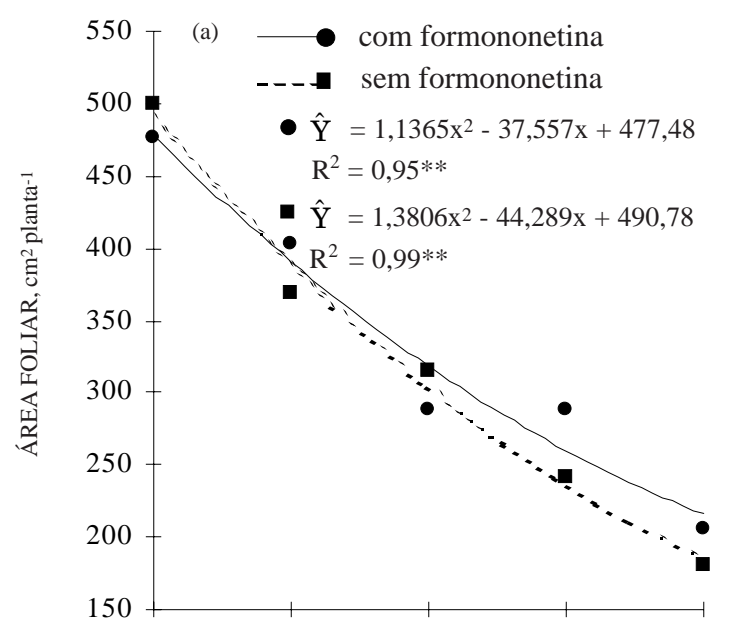

(c)

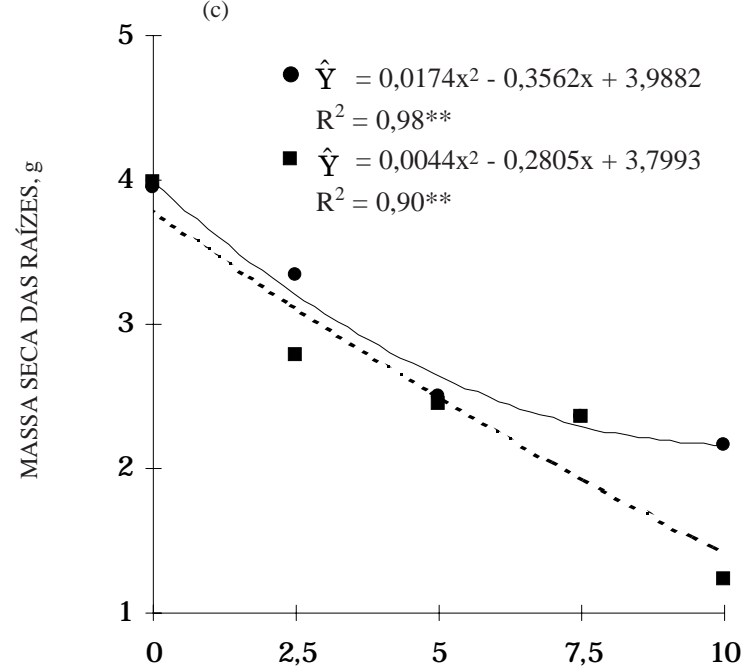

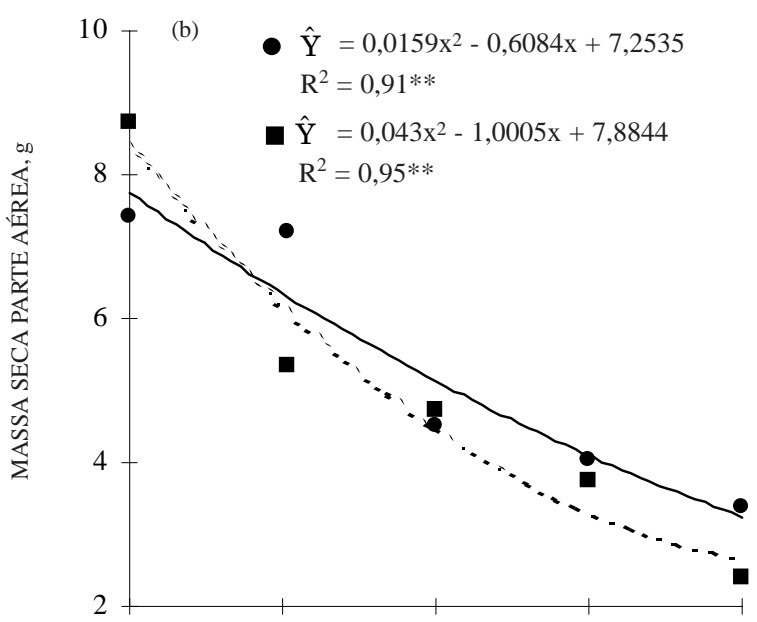

(d)

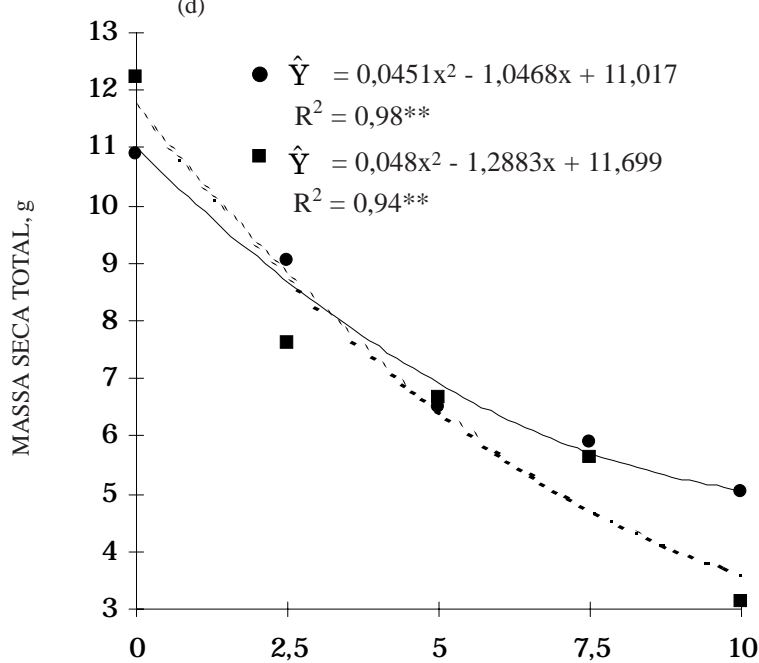

SOLO CONTAMINADO, \%

Figura 1. Crescimento do milho em função da proporção de solo contaminado com metais pesados e aplicação de formononetina no solo.

Os resultados destetrabal ho indicam que o efeito da formononetina resulta de seu efeito indireto na absorção de Zn, considerando que houve redução nos teores de $\mathrm{Zn}$ igualmente na massa seca de raízes e da parte aérea. Os teores de Cd são da ordem de 1.000 vezes menores que aqueles observados para $\mathrm{Zn}$. Estes aumentaram quase que linearmente na parte aérea em função da contaminação e praticamente não foram influenciados pela formononetina. Concentrações críticas de Cd iguais a $5 \mathrm{mg} \mathrm{kg}^{-1}$ de matéria seca (Barceló \& Poschienrieder, 1992) só foram verificadas com $5 \%$ ou mais de solo contaminado na mistura. Apesar dos elevados teores no solo, os teores de Pb e Cu na planta foram pouco afetados pelos tratamentos e por isto não são apresentados ou discutidos.

Os teores de Fe na parte aérea das plantas sem formononetina foram pouco influenciados pela contaminação do solo. Nas plantas com essa

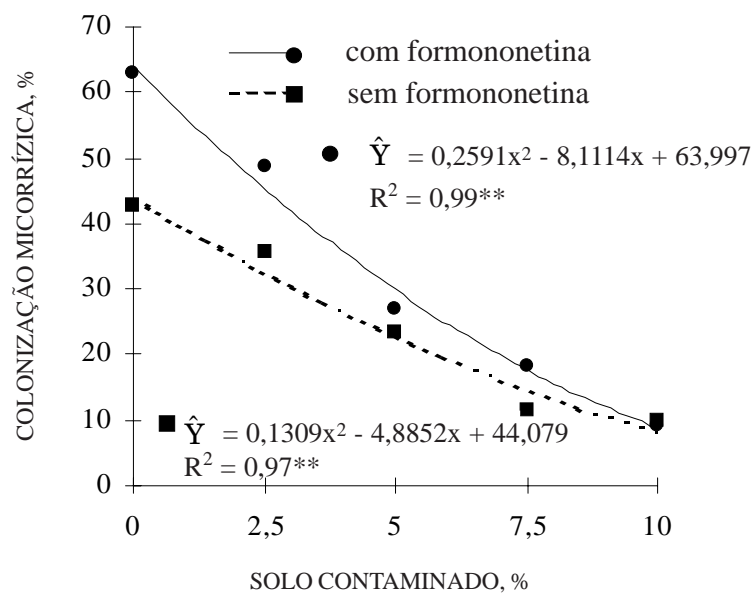

Figura 2. Colonização micorrízica do milho em função da proporção de solo contaminado com metais pesados e aplicação de formononetina. 

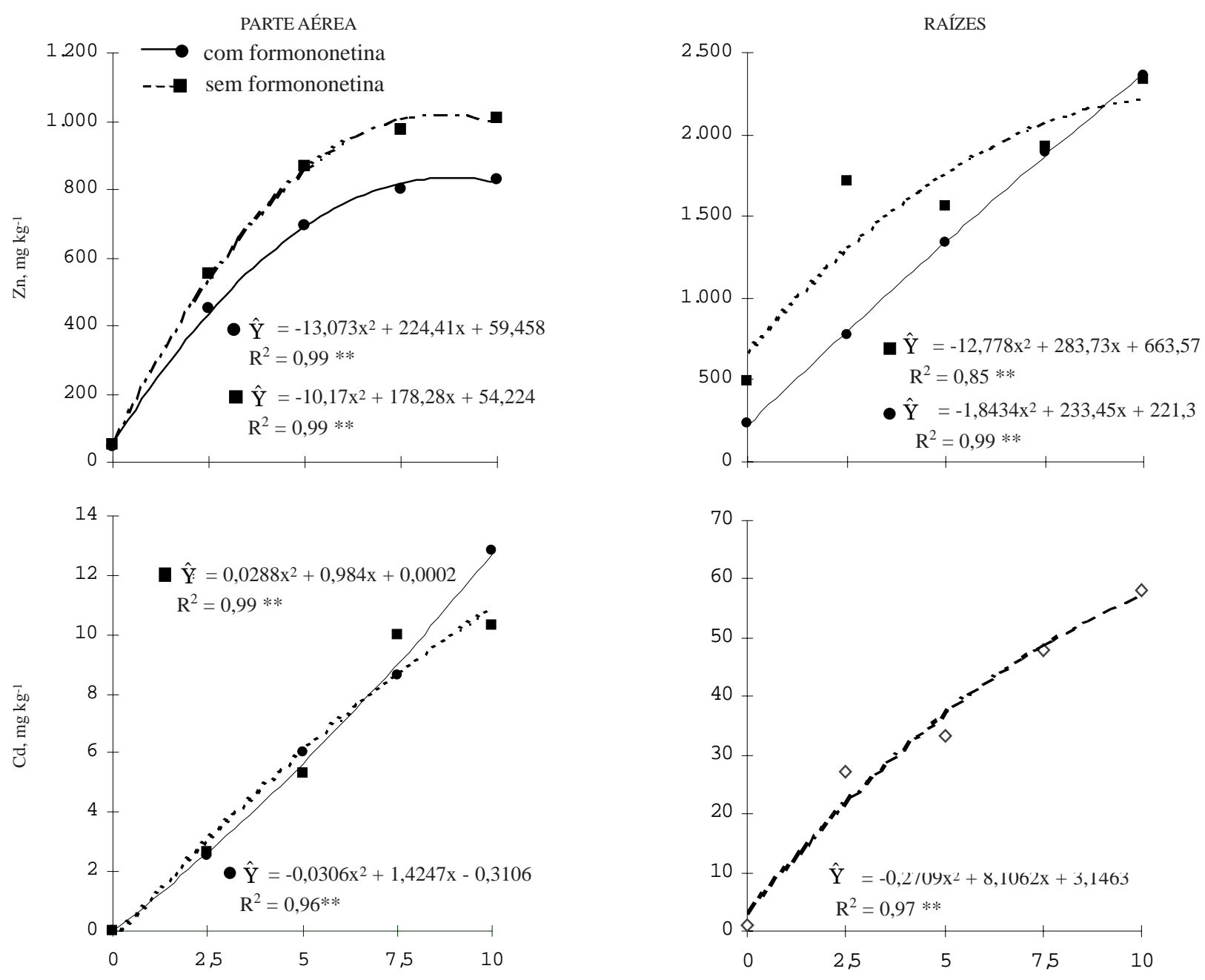

Figura 3. Teores de Zn e Cd na matéria seca da parte aérea das raízes do mi lho em função da proporção de solo contaminado com metais pesados e aplicação da formononetina.

substância, esses teores aumentaram até proporções intermediárias (em torno de 4\%) de solo contaminado, decrescendo nas doses mais elevadas (Figura 4). A formononetina aumentou em até $60 \%$ o teor de Fe do milho, em decorrência do efeito positivo dessa substância na col onização micorrízica e de descobertas recentes que mostram ser as hifas fúngi cas capazes de absorver o Fe do sol oe translocálo para plantas de sorgo (Caris et al., 1998). O milho apresentou concentrações el evadas de F e nas raízes, em média $4.000 \mathrm{mg} \mathrm{kg}^{-1}$ de matéria seca. Observouse tendência de queda no teor de Fe nas raízes com elevação da contaminação e não houve efeito significativo $(P \leq 0,05)$ para a formononetina. $O$ excesso de $\mathrm{Zn}$ tem efeito antagônico sobre o Fe, podendo atése manifestar como deficiência induzida de Fe (Alloway, 1990).De fato, a elevação na proporção de sol o contaminado reduziu a razão Fe/ Zn na parte aérea. Os valores desta razão são 1,4; 0,$17 ; 0,12 ; 0,08$ e 0,06 para plantas com

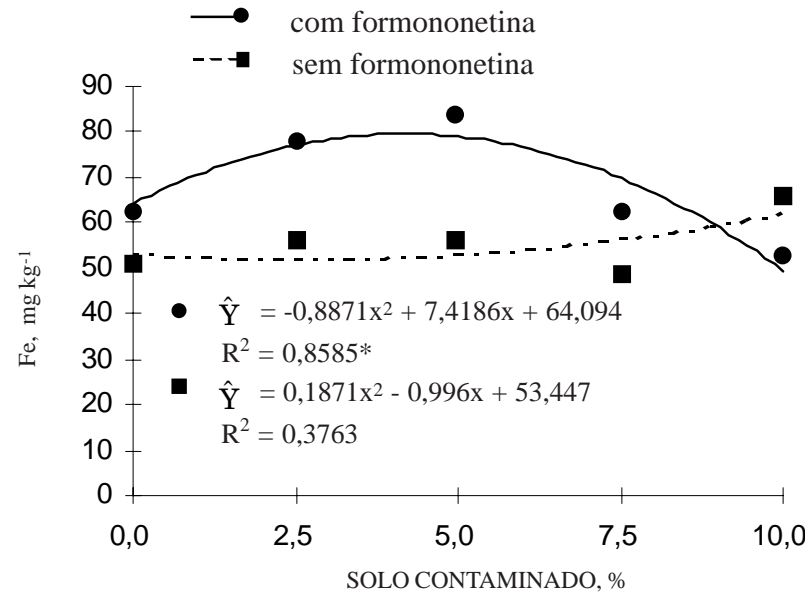

Figura 4. Teor de Fe na matéria seca da parte aérea do milho em função da proporção de solo contaminado com metais pesados e aplicação da formononetina. 
formononetina que cresceram nas misturas com 0 ; 2,$5 ; 5,0 ; 7,5$ e 10,0 de sol o contaminado, respectivamente. Tais valores são 1,$0 ; 0,10 ; 0,06 ; 0,05$ e 0,07 para as mesmas misturas de solo e plantas sem formononetina. Portanto, decresceu a razãoF e/Zn com a elevação na contaminaçãocom tendência para maiores val ores nas plantas com formononetina nas contaminações mais baixas. Como a aplicação de formononetina aumentou a absorção de Fe e diminuiu a de Zn pelo milho no solo contaminado, este pode ser um mecanismo pelo qual esta substância ameniza a toxidez de $Z n$ nesta espécie vegetal.

\section{CONCLUSÃO}

Conclui-se que a formononetina, em razão de seu efeito na micorrização, proporciona, de modo indireto, uma nutrição mi neral mais bal anceada em sol o contaminado, al iviando o estresse causado pel o excesso de Zn. O uso dessa substância pode facilitar a revegetação de sol os com excesso de metais pesados e que contenham propágul os viáveis de fungos MAs, sendo, portanto, degrandeinteressetecnológi co atual .

\section{LITERATURA CITADA}

ALLOWAY, B.J ., ed. Heavy metals in soils. New York, J ohn Wiley and Sons, 1990.339p.

BAKER, A.J .M.; McGRATH, S.P.; SIDOLI, C.M.D. \& REEVES, R.D. The possibility of in situ heavy metal decontamination of polluted soils using crops of metal-accumulating plants. Res. Conserv. Recycl., 11:41-49, 1994.

BARCELÓ, J . \& POSCHENRIEDER, Ch. Respuestas de las plantas a la contaminación por metales pesados. Suelo Planta, 2:345-361, 1992.

CARIS, C.; HORDT, W.; HAWKINS, H.J .; ROMHELD, V. \& GEORGE, E. Studies of iron transport by arbuscular mycorrhizal hyphaefrom soil to peanut and sorghum plants. Mycorrhiza, 8:35-39, 1998.

DIAZ, G.; AZCÓN-AGUILAR, C. \& HONRUBIA, M. I nfluence of arbuscular mycorrhizae on heavy metal ( $\mathrm{Zn}$ and $\mathrm{Pb}$ ) uptake and growth of Lygeum spartum and Anthyllis cytisoides. Plant Soil, 180:241-249, 1996.

DIASJ r., H.E.D.; MOREIRA, F.M.S.; SIQUEIRA, J .O. \& SILVA, $\mathrm{R}$. Metais pesados, densidade e atividade microbiana em solo contaminado por rejeitos de industria deZinco. R. Bras. Ci. Solo, 22:631-640, 1998.

DUECK, Th.A.; VISSER, P.; ERNST, W.H.O. \& SCHAT, H. Vesicular-arbuscular mycorrhizae decrease zinc toxicity to grasses growing in zinc-polluted soil. Soil Biol. Biochem., 18:331-333, 1986.

EMPRESA BRASILEIRA DE PESQUISA AGROPECUÁRIA EMBRAPA. Serviço Nacional de Levantamento e Conservação dos Solos. Manual de métodos de análise de solo. Rio de J aneiro, 1979. Não paginado.

GERDEMANN, J.W. \& NICOLSON, T.H. Spores of mycorrhizal Endogone species extracted from soil by wet sieving and decanting. Trans. Br. Mycol. Soc., 46:235-244, 1963.
GRIFFIOEN, W.A.J .; IETSWAART, J.H. \& ERNST, W.H.O. Mycorrhizal infection of an Agrostis capillaris population on a copper contamined soil. Plant Soil, 158:83-89, 1994.

GIOVANNETTI, M. \& MOSSE, B. An evaluation of techniques for measuring vesicular-arbuscular mycorrhizal infection in roots. New Phytol., 84:482-500, 1980.

LEYVAL, C.; TURNAU, K. \& HASELWANDTER, K. Effect of heavy metal pollution on mycorrhizal colonization and function: physiological, ecological and applied aspects. Mycorrhiza, 7:139-153, 1997.

NAIR, M.D.; SAFIR, G.R. \& SIQUEIRA, J.O. I solation and identification of vesicular-arbuscular mycorrhizastimulatory compounds from clover (Trifol ium repens) roots. Appl. Environ. Microbiol., 57:434-439,1991.

NOGUEIRA, A.V. As micorrizas e o excesso de metais. In: SIQUEIRA, J .O. ed. Avanços em fundamentos e aplicação de micorrizas. Lavras, Universidade Federal de Lavras, 1996. p.135-174.

SALT, D.E.; BLAYLOCK, M.; KUMAR, N.P.B.; DUSHENKOV, V.; ENSLEY, B.D.; CHET, I \& \& RASKIN, I. Phytoremediation: A novel strategy of the removal of toxic metals from the environment using plants. Biotechnol ogy, 13:468-474, 1995.

SCHÜEPP, H.; DEHN, B. \& STICHER, H. Interaktionen zwischen VA-Mykorrhizen und Schwermetallbelastungen. Angew Bot., 61:85-95, 1987.

SILVA J r., J .P. \& SIQUEIRA, J .O. Aplicação de formononetina sintética ao solo como estimulante da formação de micorrizas no milho e na soja. R Bras. Fisiol. Veg., 9:35-41, 1997.

SIQUEIRA, J .O.; SAFIR, G.R. \& NAIR, M.G. VA-micorrhizaeand mycorrhizal stimulating isoflavonoid compounds reduce plant herbicide injury. Plant Soil, 34:233-242, 1991a.

SIQUEIRA, J.O.; SAFIR, G.R. \& NAIR, M.G. Stimulation of vesicular-arbuscular mycorrhizal formation and plant growth by flavonoid compounds. New Phytol., 118:87-93, 1991b.

SIQUEIRA, J.O.\& SAGGIN J r., O.J. The importance of mycorrhizae association in natural low-fertility soils. In: SIMPÓSIO INTERNACIONAL SOBRE ESTRESSE AMBIENTAL: O milhoem perspectiva, México, 1995. Anais. SeteL agoas, EMBRAPA/CNPMS/México, CIMMYT/UNDP, 1995. p.240-280.

VALSECCHI, G.; GI GLIOTI, C. \& FARI NI , A. Microbial biomass, ativity, and organic matter accumulation in soils contamined with heavy metals. Biol. Fertil. Soils, 20:253259, 1995

VANGRONSVELD, J .; van ASSCHE, F. \& CLIJ TERS H. Reclamation of a bare industrial area contaminated by nonferrous metals: in situ metal immobilization and revegetation. Environ. Pollut., 87:51-59, 1995.

VIDAL, M.T.; ÁZCON-AGUILAR, C. \& BAREA, J .M. Effect of heavy metals ( $\mathrm{Zn}, \mathrm{Cd}$ and $\mathrm{Cu}$ ) on arbuscular mycorrhiza formation. In: ÁZCON-AGUILAR, C. \& BAREA, J .M., eds. Mycorrhizas in integrated systems from genes to plant development In: EUROPEAN SYMPOSIUM ON MYCORRHIZAS, 4., Granada, 1994. Proceedings. Granada, European Commission, 1996. p.487-490.

WEISSENHORN, I.; LEYVAL, C.; BELGY, G. \& BERTHELIN, J . Arbuscular mycorrhizal contribution to heavy metals uptake by maize (Zea mays L.) in pot culture with contaminated soil. Mycorrhiza, 5:245-251, 1995. 